\title{
Los refugiados guatemaltecos y la frontera-frente de discriminación, explotación y desigualdad*
}

\author{
VERÓNICA RUIZ LAGIER**
}

\begin{abstract}
Guatemalan Refugees ANd the $F$ RONT-BORDER OF DiscriminaTION, EXPLOITATION AND INEQUALITY. This work aims to give an historical and sociocultural content to the category of border, through the case of Guatemalan refugees that entered Mexico in 1981. The South border is analyzed from a socio-geographical position and the long term historical perspective. The border area is conceived as a territorialized space, in which the population that sought refuge and naturalized in Mexico anchors its new identity. It is an exam of the concept of refuge as a non-homogenous process, where the border is defined from contradictory relations of solidarity, racism and inequality in the inhabited space.
\end{abstract}

Key words: refuge, territorialized space, citizenship, racism

\section{Introducción}

ntes de que la población guatemalteca se refugiara en México existía en Chiapas y en la zona fronteriza - con Guatemala una historia común de flujos poblacionales, que ha llevado a diferentes autores a hablar de la existencia de una misma región sociocultural, con una identidad colectiva basada en una historia colonial común, en procesos similares de independencia, así como en relaciones de intercambio económico, explotación y represión social.

Recordemos que en 1528 llegaron los conquistadores españoles a Chiapas provenientes de Guatemala, y que en 1544 Chiapas dependió de la sede de Guatemala. Fue hasta 1824 que se anexa Chiapas a México, y en 1842 lo hizo el Soconusco; pero la actual frontera internacional se fijó hasta 1882 (De Vos, 2002: 52-53).

Esto significa que la frontera no es estática e inamovible, al contrario, debemos entenderla como el resultado de un proceso histórico en el que la población establecida en ambos lados de ella no deja de tener contacto entre sí. Sin embargo, la mayoría de las veces, la frontera se concibe como una barrera definida y permanente.

\footnotetext{
* Artículo recibido el 05/06/17 y aceptado el 22/11/17.

** Instituto Nacional de Antropología e Historia, Dirección de Etnología y Antropología Social. Av. San Jerónimo 880, col. San Jerónimo Lídice, Magdalena Contreras, 10200, Ciudad de México <veronicalagier@gmail.com>.
}

\begin{abstract}
Resumen
trabajo busca dar un contenido histórico y sociolos refugiados guatemaltecos que ingresaron a México larga duración. El espacio fronterizo se concibe como se refugió y naturalizó en México ancla sus nuevas identidades. Se examina el refugio como un proceso no omogéneo, y se define la frontera desde las relaciones
\end{abstract} Palabras clave: refugio, espacio territorializado, ciudadanía, racismo 
Según explica Jan De Vos, esto tiene que ver con una mala traducción del inglés al castellano, pues tanto border como fronter se traducen como sinónimos en castellano, cuando, en realidad, la segunda alude a una barrera ancha, móvil, dinámica e indefinida (De Vos, 2002: 50). Por ello, es diferente hablar de fronteralímite, como línea de separación entre entidades, fijada según criterios geopolíticos, que defrontera-frente, que se refiere a un sistema de expansión en un espacio que se considera "vacío", ya sea por motivos colonialistas, de producción, etcétera.

En el caso de la frontera sur de México, la fronterafrente ha avanzado o retrocedido según las circunstancias. Comenzó con los proyectos coloniales de expansión y dominación en el área maya derivados de las divisiones administrativas españolas; y se convirtió en frontera-límite hasta 1882 .

Por otro lado, para que una frontera funcione como límite, debe formar parte de la conciencia social, lo cual ocurre sólo cuando los pueblos que están divididos por la frontera (en términos jurídicos) no se identifican histórica y culturalmente (Pohlenz, 1985: 29). Ninguna de estas cosas sucede en la frontera sur de México, y, al contrario, mucha de la población de un lado y otro de la "línea" ha convivido de manera cotidiana y compartido una historia política, económica y social, de estilos de vida, modos de hablar, prácticas religiosas, sistemas de producción, y también divisiones raciales y antagonismos sociales con las poblaciones del norte de Guatemala. Hoy día, lo que se registra como migración centroamericana a territorio mexicano es, quizás, parte de los históricos desplazamientos territoriales dentro de un mismo entorno cultural (Gutiérrez, 2001: 23).

Lo cierto es que la frontera no puede ser reducida a un concepto, sino que debe considerarse un espacio socialmente construido. Siguiendo la propuesta de los estudios de frontera efectuados desde la geografía histórica y cultural, reflexiono sobre casos particulares en temporalidades de corta o mediana duración, y centro mi discusión en las prácticas sociales y en las representaciones de los sujetos, como un elemento que influye en la constitución de la frontera. ${ }^{1}$ Respecto a Chiapas, tomo como eje transversal de análisis el racismo y la discriminación, entendiéndolos como prácticas de un grupo de poder que inferioriza y excluye al otro con base en su diferencia cultural y que, en el caso de los indígenas chiapanecos y los refugiados guatemaltecos, se realiza a través de relaciones de explotación. ${ }^{2}$

\section{La frontera sur como un proceso de larga duración}

Para hablar de la frontera sur, es necesario verla con un lente histórico que dé cuenta de sus transformaciones. Guatemala y México tienen una historia común de colonialismo y comparten episodios importantes de liberación y conformación del Estado independiente. No es extraño que la frontera geográfica se haya modificado en distintos momentos, y que quienes hoy son considerados foráneos en Chiapas hayan sido pobladores un siglo atrás. Por tanto, creo esencial recordar al lector algunos datos referentes a la conformación de la frontera sur en el siglo xIX.

La antigua Capitanía General de Guatemala (que comprendía el actual territorio del estado de Chiapas, México) finalizó el 15 de septiembre de 1821 con la firma del Acta de Independencia de América Central. No sobra decir que en 1824 fue la población no indígena la que mediante plebiscito decidió pertenecer a México y no a Guatemala (Hernández, 2012: 56).

Con la Reforma Liberal iniciada en 1871 en Guatemala, muchos pueblos expropiados de sus tierras viajaron a colonizar "terrenos baldíos" al norte de su país. Es el caso de numerosos pueblos jacaltecos, chujes, q'anjobales, mochós, etcétera, que hoy habitan la frontera sur de México, porque en 1882, con el Tratado de Límites entre los dos países, la frontera se modificó: en el Soconusco, Guatemala avanzó hasta el río Suchiate, y México recibió la comarca de Motozintla (De Vos, 1993). Poco después, el gobierno de Porfirio Díaz emitió la Ley de Colonización, promoviendo así la ocupación de los terrenos nacionales aledaños a la recién creada línea fronteriza. En esa época, la población hablante de q'anjobal, chuj, jacalteco y mam originaria de Guatemala se asentó en la frontera chiapaneca (o ya estaba asentada), naturalizándose posteriormente como ciudadanos mexicanos (Hernández, 2012: 49).

\footnotetext{
1 "En los campos de la geografía histórica y la geografía cultural, es donde más se ha notado la influencia de la tesis de la frontera como representación de espacio poscolonial. En general, estos trabajos se caracterizan por ser estudios de caso particulares en temporalidades de corta o mediana duración. Igualmente centran sus discusiones, además de las prácticas sociales, en las representaciones de los sujetos como un elemento que influye en la constitución de las fronteras" (Arriaga Rodríguez, 2011: 88).

2 De acuerdo con Oliver C. Cox: "el prejuicio racial es una actitud social propagada entre la gente por una clase explotadora, a fin de estigmatizar a algún grupo como inferior, de modo que tanto la explotación del grupo como la de sus recursos pueda justificarse" (cit. en Arellano Sánchez y Santoyo, 1996: 146).
} 
Fue entonces que el Tratado de Límites dividió a los pueblos indígenas a ambos lados de la frontera, y así es documentado por Aída Hernández, que para el caso de los pueblos jacaltecos (poptí) nos dice:

La nueva frontera partió en dos el territorio jacalteco y los habitantes fronterizos tuvieron que optar por nacionalizarse mexicanos o regresar a Guatemala. Según documentos del xix encontrados en el ejido Paso Hondo, los procesos de nacionalización se dieron más bien de manera automática al quedarse los pueblos en territorio mexicano y no reclamar la nacionalidad guatemalteca... La ciudadanización legal de esta población no implicó una ruptura de los vínculos con Guatemala... [Hernández, 2012: 85].

Por lo anterior, insisto en que la frontera-frente es la que se ha movido en diferentes momentos históricos, y pretende limitar el libre tránsito de quienes conciben ese espacio como propio porque ha sido así desde tiempos ancestrales. Son los Estados-nación los que surgen y se transforman, pero los pueblos originarios han habitado ese espacio antes de su creación.

En el caso de los chujes mexicanos, establecidos en la comunidad fronteriza de Tziscao, los pobladores recuerdan que fue en 1870 cuando un grupo de diez familias procedentes de la finca Chaculá, en San Mateo Ixtatán, Huehuetenango, se instaló en las inmediaciones de la laguna, a la que llamaron Tziscao, que quiere decir "puente truncado", haciendo referencia a un puente de piedra que divide la laguna en dos. No muy lejos de ahí, en lo que hoy es el ejido Guadalupe Victoria, se asentó en 1871 la primera población poptí conocida como el Huixquilar (Hernández, 2012: 78, 92-93).

En cuanto a los mames, su presencia en la zona del Soconusco es incluso anterior al Tratado de Límites, pues laboraban en las fincas cafetaleras propiedad de alemanes y funcionarios mexicanos. A la fecha, continúan trabajando el café, enfrentando condiciones tan marginales como las de la primera mitad del siglo xx. Asimismo, afrontan un desplazamiento lingüístico y un cambio cultural violento que derivan del contexto de discriminación y pobreza al que son sometidos por el gobierno mexicano.

Para entender la dinámica social y económica de finales del siglo xx y principios del xxI en ambos lados de la frontera, es revelador leer a Manuela Camus, quien nos dice:

Huehuetenango es un departamento donde la histórica impronta fronteriza supone altos niveles de comercio, contrabando, trasiego de trabajadores y flujos culturales intensos entre ambos lados (mexicano y guatemalteco). Es un espacio de paso de transmigrantes que llegan de cualquier lugar de Guatemala, de Centroamérica y aun de Sudamérica; pero donde hay que agregar que sus mismos pobladores han sido y continúan siendo migrantes tradicionales hacia la bocacosta guatemalteca, hacia el Soconusco y Chiapas por trabajo agrícola, o a Cancún ocupándose en el servicio doméstico o en la construcción, y ahora son pioneros, "especialistas en la salida hacia el Norte" [2007: 25].

Camus se apoya en el trabajo de Carlos Navarrete (1980) para analizar la comunicación histórica que existe en ambos lados de la frontera, incluso en aquellos pueblos en apariencia apartados en áreas marginales de la alta montaña de los Cuchumatanes guatemaltecos, donde se ha construido una compleja red de veredas que entroncan con la región de Chiapas y el sur de Guatemala:

estas cumbres son atravesadas por pasos y callejones facilitando la distribución de caminos. En sus flancos se engarzan los que vienen por el río Grijalva y los altos de Chiapas. Hay varias conexiones posibles en la Selva Lacandona, y por lo menos dos salidas que conducen a Las Verapaces y a todo el sistema occidental de Guatemala. Existen dos salinas importantes que podrían explicar mucho de la concurrencia de caminos; sobre todo vistas como parte de una cadena de salinas de altura fundamentales para la economía indígena viniendo desde Iztapa en México; pasando por la Depresión de Chiapas a Portatenco; continuando en Sacapulas y rematando en "los Nueve Cerros" en la cuenca del Chixoy o Río de Las Salinas que corre a formar el río Usumacinta [Camus, 2007: 26].

Como vemos, existe una historia cultural y socioeconómica común en la zona donde fue establecida la frontera política, pero la realidad fronteriza es vivida de diferentes formas por cada uno de los grupos sociales que la habitan, dependiendo también de las condiciones sociopolíticas del momento. Por ejemplo, en el lado guatemalteco, con la Revolución de 1944 (derrocada diez años después) la población sufrió el retroceso de reformas y derechos sociales adquiridos. Esto derivó en la organización militar y clandestina de los años setenta, que el gobierno militar enfrentó particularmente a principios de los años ochenta, haciendo uso de violencia desmesurada y arrasando a todos los pueblos que eran considerados base de apoyo y raíz contrainsurgente. Fue así que a partir de 1981 cruzaron la frontera a Chiapas más de 100 mil indígenas guatemaltecos (Freyermuth y Godfrey, 1993: 23). 
En diversas ocasiones, el ejército guatemalteco traspasó la frontera-límite buscando liquidar a la población refugiada a la que consideraba base de apoyo de la guerrilla, y éste fue uno de los motivos por los que el Estado mexicano decidió en 1984 reubicar a los refugiados en los estados de Campeche y Quintana Roo. Otra razón de peso fue evitar que la experiencia política de Guatemala coincidiera con la que comenzaba a surgir en las cañadas de Chiapas. De hecho, años después, en 1994, el levantamiento zapatista sorprendió al mundo con su declaración de guerra al Estado mexicano, y es sabido el intercambio de experiencias organizativas que hubo entre algunos miembros de los grupos rebeldes de Guatemala con quienes formaron el Ejército Zapatista de Liberación Nacional. ${ }^{3}$

\section{El refugio guatemalteco y la frontera-frente}

Sobre el proceso de refugio he hablado en otros trabajos (Ruiz Lagier, 2012a, 2012b; Muñoz y Ruiz Lagier, 2014). Para el objetivo de este estudio baste mencionar que, según cifras oficiales de la Comisión Mexicana de Ayuda a Refugiados (Comar), entre 1981 y 1982 sólo ingresaron a territorio mexicano 40 mil refugiados guatemaltecos y que de 1993 a 1999, durante el Programa de Retorno Colectivo, organizado junto con el Alto Comisionado de las Naciones Unidas para los Refugiados (ACNUR) y organizaciones no gubernamentales internacionales, retornaron 23 mil personas a Guatemala (aunque no se distingue entre refugiados y sus hijos ya nacidos en México). En paralelo a este programa, la Secretaría de Relaciones Exteriores realizó un Programa de Estabilización Migratoria, con el que se naturalizaba a quienes no accedían a regresar a su país y, según la Comar, se otorgaron diez mil cartas de naturalización hasta 2005. ${ }^{4}$ A diferencia de la visión oficial, la Diócesis de San Cristóbal registró el ingreso de cuando menos 100 mil refugiados, a los cuales brindó alimento y atención médica ante la pasividad del gobierno mexicano que no enfrentaba la emergencia humana, y que incluso prohibía el ingreso de la población que buscaba escapar de la embestida del ejército guatemalteco (Montejo, 1999).

Sin duda, no existió un proceso homogéneo de refugio en Chiapas, ni tampoco en Campeche o Quintana Roo, donde los refugiados fueron desplazados con violencia por el gobierno mexicano en 1984 para alejarlos de los límites fronterizos (Franco, 1999: 79). La población que fue trasladada a estos dos estados tiene un proceso de integración distinto y, por lo tanto, de organización comunitaria. Y dentro del propio estado de Chiapas es categóricamente distinto el proceso de quienes quedaron dentro de los campamentos al de aquellas familias que ingresaron en comunidades indígenas mexicanas o en rancherías como "posados", sobre todo en la selva chiapaneca.

De acuerdo con lo que he visto desde 2002 en las poblaciones de origen guatemalteco, la historia política de refugio e integración definitiva a México determina el nivel de desarrollo social, de participación política en la región, de cohesión comunitaria e identidad como pueblos indígenas (akateko, q'anjobal o chuj ahora mexicano). Esto lo he observado de manera señalada en comunidades akatekas establecidas en el municipio La Trinitaria, las cuales poseen un origen común, pero un proceso de refugio e integración que hace que tengan hoy día condiciones socioculturales muy distintas, a pesar de su parentesco y comunicación permanente. Asimismo, sólo las comunidades con mayor organización desde la etapa del refugio han conseguido que el gobierno municipal y estatal les proporcione servicios básicos de educación, salud, energía eléctrica e infraestructura comunitaria (caminos pavimentados, salón de actos, oficinas ejidales), etcétera.

En cambio, aquellas familias que ingresaron a Chiapas y se establecieron como "posados" en rancherías mexicanas y no organizadamente en campamentos, se encuentran sin documentos oficiales y en condiciones de total vulnerabilidad, en tanto se les presta un pedazo de tierra donde vivir a cambio de que la familia completa trabaje para el patrón. Por lo general, no tienen papeles que los acrediten como guatemaltecosrefugiados, ni como mexicanos, por lo que no acceden a programas sociales y se mantienen en un círculo vicioso de marginalidad.

Igual sucede a quienes ingresaron en comunidades indígenas. Se conformaron como minorías étnicas que muchas veces son discriminadas por el resto de la población local; se les exige cumplir con trabajos colectivos o cuotas económicas, pero sin derecho a decidir o participar en la vida política comunitaria. No pueden trasladarse a ninguna ciudad por miedo a ser detenidos por las patrullas de migración, no tienen recursos ni capital cultural para gestionar sus documentos migratorios; y, por no estar organizados

3 “En 1994, guerrilleros guatemaltecos 'suministraron armas al EzLN”, en Proceso, núm. 2138,30 de diciembre de 2000 <http: / / www.proceso.com.mx/ 184546/en-1994-guerrilleros-guatemaltecos-ldquosuministraron-armas-al-ezln-rdquo> [21 de noviembre de 2017].

4 Véase http: / /www.comar.gob.mx/es/COMAR/El_refugio_guatemalteco [21 de noviembre de 2017]. 


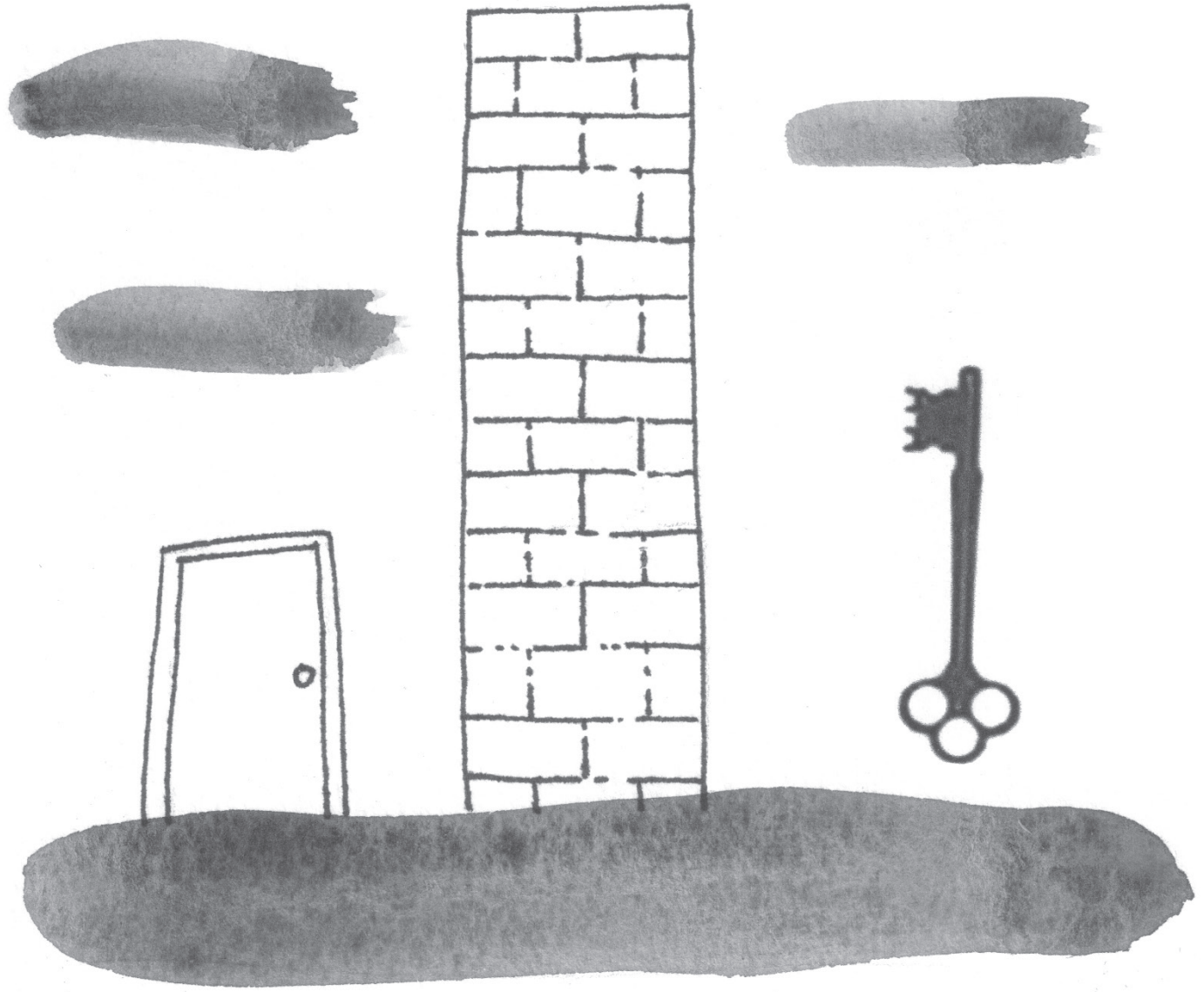

ni en contacto con el resto de la población refugiada naturalizada, no acceden a los beneficios de campañas extemporáneas de regularización migratoria, que han sido creadas en diversos momentos para los refugiados que no finalizaron este proceso. No son ni de aquí ni de allá. Aunque tienen hijos y nietos nacidos en Chiapas, con frecuencia el registro civil rechaza registrarlos, perpetuando así las condiciones de marginación.

Un problema similar enfrentan quienes retornaron a Guatemala en el Programa de Retorno Colectivo (a partir de 1993) y poco después regresaron a Chiapas ante el incumplimiento de acuerdos y la falta de seguridad. Al ingresar otra vez a México lo hicieron como indocumentados, ya no como refugiados. Marco Tulio Miguel Mateo, q'anjobal de Nuevo Huixtán, habla de lo difícil que le es sobrevivir por no tener documentos que lo identifiquen como guatemalteco ni como mexicano:

Nací en la aldea Momolá, en Barillas, Guatemala. Aproximadamente tengo 35 años. A los 18 años empecé a buscar maneras [de naturalizarse]. Cuando vino el lla- mado del [programa] extemporáneo participé, pregunté, anduve, sacaba constancias con las autoridades de aquí, pero ni por eso [aceptaron las autoridades de migración]. Me decían que tenían que tener papeles mis padres, pero ellos no tienen, no se puede. Quiero luchar para salir adelante pero no puedo. Yo diría que es como una cadena gruesa que me tienen tendido en el paso y no puedo cruzar ¿qué hago? ¡No puedo!

Le digo sinceramente, porque lo sé... son cinco años que fuimos a Guatemala cuando nos fuimos a retornar y durante los cinco años no me gustó, así que la mayor parte de mi vida la he vivido aquí en Huixtán. Yo me siento que soy de aquí, me siento que aquí nací, y creo que aquí voy a morir. Yo lo diría de esta manera: mis padres decían que son de allá, ipero yo no! Por eso digo, aquí donde vivo me siento bien, si aquí no me corren, nunca me iré. ${ }^{5}$

La situación de Marco Tulio es la de cientos de familias en la zona selva. La Comar ya no consideró refugiados a quienes aceptaron el retorno colectivo en 1993, así hayan vuelto a las pocas semanas. Tampoco presionó al gobierno guatemalteco para que cumpliera

5 Testimonio de Marco Tulio Miguel Mateo, Nuevo Huixtán, 2010. 
los acuerdos establecidos para el retorno seguro y colectivo. Cientos de familias regresaron a México nuevamente sin documentación. Desde entonces son invisibles.

Marco Tulio limpia la milpa de otros mexicanos, corta leña, trabaja como carpintero, y cría a los hijos de sus hermanos mayores que sí lograron naturalizarse y laboran como albañiles en Quintana Roo. Todos viven en una pequeña casita de madera que Marco Tulio construyó. Los niños no están registrados, no van a la escuela, es un círculo de pobreza y marginación.

Para ellos, la regularización migratoria es una pesadilla y una condición inalcanzable, pues los registros civiles en sus aldeas fueron quemados en la guerra, y para adquirir un acta de nacimiento deben ir a la capital guatemalteca a tramitarla con dos testigos. En caso de lograr concluir ese trámite, deben regresar un par de meses después por el documento que los acredita nacidos en Guatemala, y con éste comenzar el trámite migratorio en Chiapas. Si no quieren ser tratados como migrantes recién llegados a México, deben asistir a las oficinas de migración con una carta de sus autoridades ejidales que sostienen su estancia en México, más dos testigos de su comunidad, y pagar el proceso migratorio.

La pregunta es cómo un campesino podría pagar todos esos gastos de traslado y trámite administrativo, más los viáticos de sus testigos en Guatemala y México, que suman cuando menos 70 mil pesos. Muchos de ellos son peones que sólo acceden a un pago de 70 pesos la jornada en la temporada de siembra o cosecha. El resto del año se subsiste con productos de autoconsumo o trueque.

El Programa de Retorno Colectivo ha sido considerado "exitoso" por quienes estudian temas de política internacional; no obstante, quienes trabajamos con métodos etnográficos percibimos sus limitaciones, sin seguimiento institucional y sin programas sociales que apoyen a la población en su proceso de integración definitiva al país de bienvenida.

Por lo tanto, al hablar del refugio guatemalteco y el proceso de integración, es indispensable reconocer que la población involucrada experimenta en la actualidad cuando menos tres condiciones:

- Los naturalizados por la Comar ubicados regularmente en excampamentos, hoy comunidades fronterizas.

- Los refugiados no registrados por la Comar que se integraron individualmente a rancherías mexicanas o comunidades indígenas fronterizas, y no cuentan con documentos migratorios.
- La población que retornó organizadamente y regresó a México en calidad de indocumentada desde hace por lo menos 34 años.

Esta clasificación resulta muy útil al hablar con las autoridades de Relaciones Exteriores, pues no se trata de nuevos migrantes sino de población que no ha concluido su proceso de documentación.

La vulnerabilidad generada por la incertidumbre jurídica en la población refugiada puede ejemplificarse mediante el episodio conocido entre ella como La guerra de las canicas. En 2008, Nueva Poza Rica, ubicada en el municipio Las Margaritas, se desarrolló como una zona comercial regional importante. La habilidad de la población refugiada para comercializar en la zona fronteriza es muchas veces mayor que la de la mexicana, y ésta comete abusos sabiendo de la vulnerabilidad de los indocumentados. Un comerciante de origen guatemalteco ganó muchísimo dinero porque se le ocurrió vender canicas. Vendió tanto, que los mexicanos de la localidad se molestaron y prohibieron la venta de canicas, incluso amenazaron con encarcelar a los padres de los niños que las compraran.

Este suceso, que pudiera resultar gracioso, es reflejo de cómo la experiencia del refugio empuja a la población a buscar siempre formas novedosas para obtener ingresos, y de cómo la fragilidad jurídica los debilita para enfrentar la desigualdad y la ley consuetudinaria de quienes les han dado posada desde hace 35 años. Asimismo, este hecho fue motivo de queja ante la Comisión Estatal de Derechos Humanos, y ayuda a entender cómo en la cotidianidad la población refugiada no es plenamente sujeto de derecho.

\section{La discriminación y sus prácticas de reproducción}

Por lo general, cuando se alude a la frontera, se omite hablar de las relaciones de racismo y discriminación que ahí se reproducen, donde los indígenas de origen guatemalteco son colocados en el último peldaño de la escala social. Lo anterior tiene que ver con una historia larga de racismo que desde la época colonial vive particularmente la región maya, diferenciando a la población por raza, color de piel, así como elementos culturales centrados en la etnicidad, y generando procesos de degradación, discriminación, humillación y explotación humana (Arellano Sánchez y Santoyo, 1996: 142).

Si bien al inicio de la tragedia del refugio guatemalteco los mexicanos que vivían en la zona fronteriza se solidarizaron, y hay casos en verdad conmovedores, 
también es cierto que más tarde éstos consideraron que la infraestructura y ayuda humanitaria que llegaba a los campamentos de refugio hacía falta en toda la región, pues compartían los mismos índices de pobreza. Las acciones federales dirigidas a la población refugiada no siempre fueron las más adecuadas. Al mantener tantos años la ayuda humanitaria dentro de los campamentos, se generaron relaciones de dependencia que posteriormente, al retirar los programas humanitarios, afectaron aún más a la población naturalizada, que se vio obligada a migrar a Estados Unidos para sobrevivir.

Hay que insistir en un aspecto central: los refugiados eran en su mayoría campesinos. La Diócesis de San Cristóbal (a través del Comité Cristiano de Solidaridad) ayudó algunas veces a la compra de terrenos para establecer de manera temporal a los guatemaltecos, pero nunca se les proporcionaron terrenos de cultivo porque se pensaba que, firmada la paz en Guatemala, la población retornaría a su país. Esto no sucedió así: un porcentaje importante de refugiados decidió no regresar, quedándose en Chiapas como campesinos naturalizados pobres y sin tierra. El ACNUR finalizó su trabajo con los refugiados guatemaltecos en 2005 y no otorgó recursos para la compra de las tierras donde se ubicaban los campamentos, ni ofreció recomendaciones sobre este tema al gobierno mexicano. La Comar no le dio seguimiento a este problema y los refugiados comenzaron a migrar a Estados Unidos a fin de ganar los recursos necesarios para adquirir tierras de cultivo o regularizar el régimen de propiedad de los terrenos que habitaban como campamentos de refugio.

Por lo común, las rancherías mexicanas fueron dotadas de servicios gracias a la gestión de las comunidades de origen guatemalteco, que por su número de habitantes y organización han conseguido servicios básicos y recursos para proyectos productivos. No obstante esta habilidad para enfrentar su difícil condición, siguen siendo discriminados por la población aledaña o los funcionarios municipales que suelen llamarlos despectivamente "chapines" o refugiados.

Si bien hay grupos y organizaciones que desde hace 20 años comenzaron a tejer vínculos políticos con la población refugiada, por lo general los líderes municipales acuden a estas comunidades sólo en periodos electorales, prometiendo resolver problemas de regularización agraria y migratoria que rebasan su voluntad y capacidad política, porque están fuera de su jurisdicción. Lo cierto es que las campañas electorales dividen a las comunidades, enfrentan a sus líderes históricos, y compran las voluntades de las nuevas generaciones, que deberían estar fortaleciendo el proyecto comunitario.
Los espacios que generaban organización, cohesión e identidad colectiva en los excampamentos de refugio, como eran la escuela y la clínica de salud, fueron absorbidos por el Estado a finales de los noventa, y con ello poco a poco se ha limitado la capacidad de acción de los promotores de salud y de las parteras, que son quienes están cotidianamente con la población atendiendo sus emergencias.

Un ejemplo es Nuevo Huixtán, donde se dieron experiencias organizativas interesantes en torno al campo de la salud, que el gobierno estatal ha desconocido, porque generan conciencia colectiva. Los promotores de salud que atendían los campamentos de refugio en esta región fueron formados desde Guatemala por sacerdotes católicos que habían hecho trabajo organizativo. Por otro lado, en Chiapas había trabajo pionero del hospital de Comitán, que tenía un programa con el Instituto Politécnico Nacional y dos planes: Plan Tojolabal y Plan Selva, perfilados por miembros del movimiento médico, que diseñaron en la región fronteriza trabajo novedoso en los ochenta para las comunidades donde no existía servicio de salud. El modelo era muy participativo, no sólo de capacitación sino de movilización social, en un momento en el cual la única presencia del Estado eran las campañas contra el paludismo. En ese contexto llegaron los refugiados, pero con la experiencia de Guatemala que se amalgamó con la de Chiapas, y a la que siguió la de organizaciones civiles. Esto fue el modelo para las

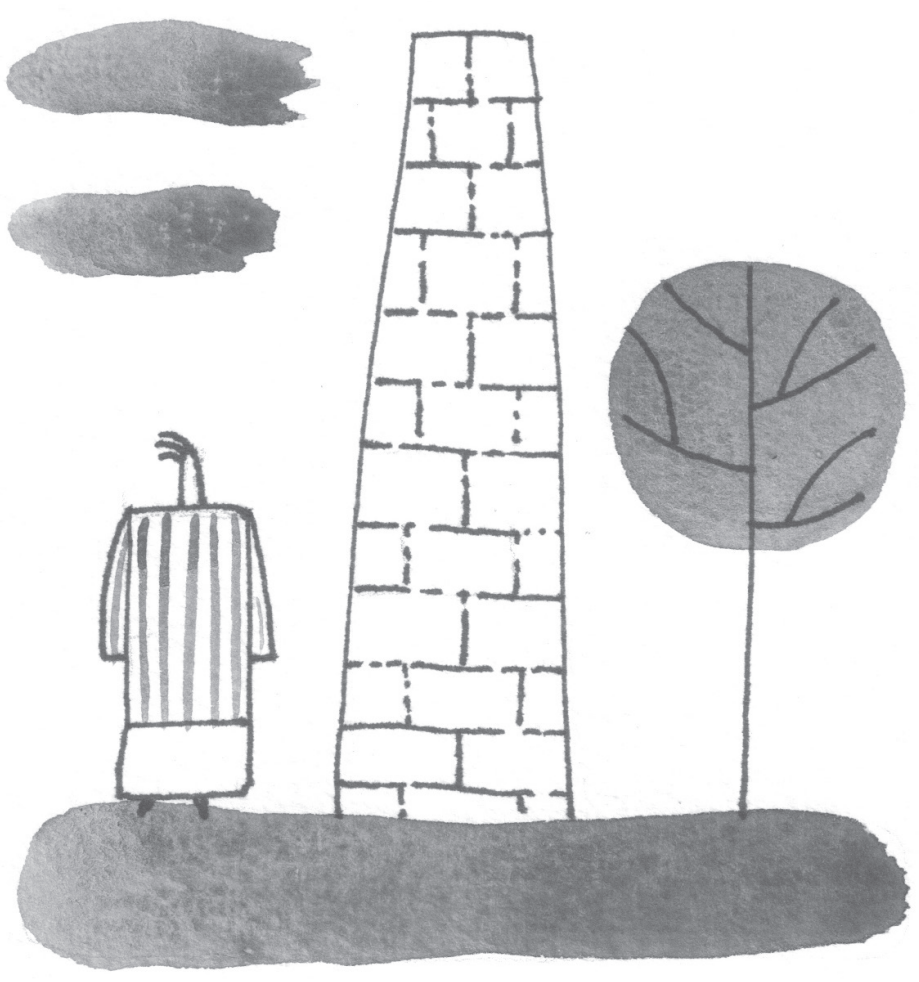


comunidades zapatistas, todo su esquema y acción de salud fue retomado de esta experiencia de refugio. ${ }^{6}$

Desde la década de los noventa, cuando el gobierno mexicano ejerció el control sobre los servicios de educación y salud, se ha desmovilizado a la población y las consecuencias son catastróficas, asegura el doctor Marcos Arana, fundador del Centro de Capacitación en Ecología y Salud para Campesinos, porque tampoco el Estado tiene la capacidad y la voluntad de retomar la experiencia colectiva que resuelve con mayor rapidez las condiciones de prevención y atención en las comunidades.

Nuevo Huixtán ilustra con nitidez lo anterior:

tiene una unidad del Imss-Oportunidades y otra de la Secretaría de Salud, que prometía convertirse en un hospital, y por ello la gente participó con mano de obra y materiales (como lo hacía en el periodo del refugio). Finalmente las autoridades la dejaron como clínica de atención de primer nivel. Ahora hay una línea invisible en la comunidad que divide a la población entre los que se atienden en una u otra clínica, erosionando incluso el tejido social pues funciona sin ninguna participación de la comunidad, dejando atrás la gran experiencia organizativa del refugio en la que la comunidad tenía su Casa de Salud, promotores y parteras que atendían a toda la población. ${ }^{7}$

¿Cómo reconfigurarse como actores sociales bajo las condiciones actuales de marginación, discriminación e inmovilización político-cultural? La capacidad de gestión no la posee la actual generación de mayas de origen guatemalteco, sólo tiene recuerdos familiares de la guerra, del refugio, la pobreza, la posibilidad de migrar para sobrevivir y mantener a sus padres que ya están cansados de desplazarse.

\section{El desplazamiento permanente en las fronteras}

Para quienes viven en ambos lados de la frontera sur de México, la línea es su territorio. Conocen las rutas que les permiten llegar a las aldeas guatemaltecas sin pasar por ninguna oficina migratoria. Así, del lado mexicano encontramos venta de pan recién

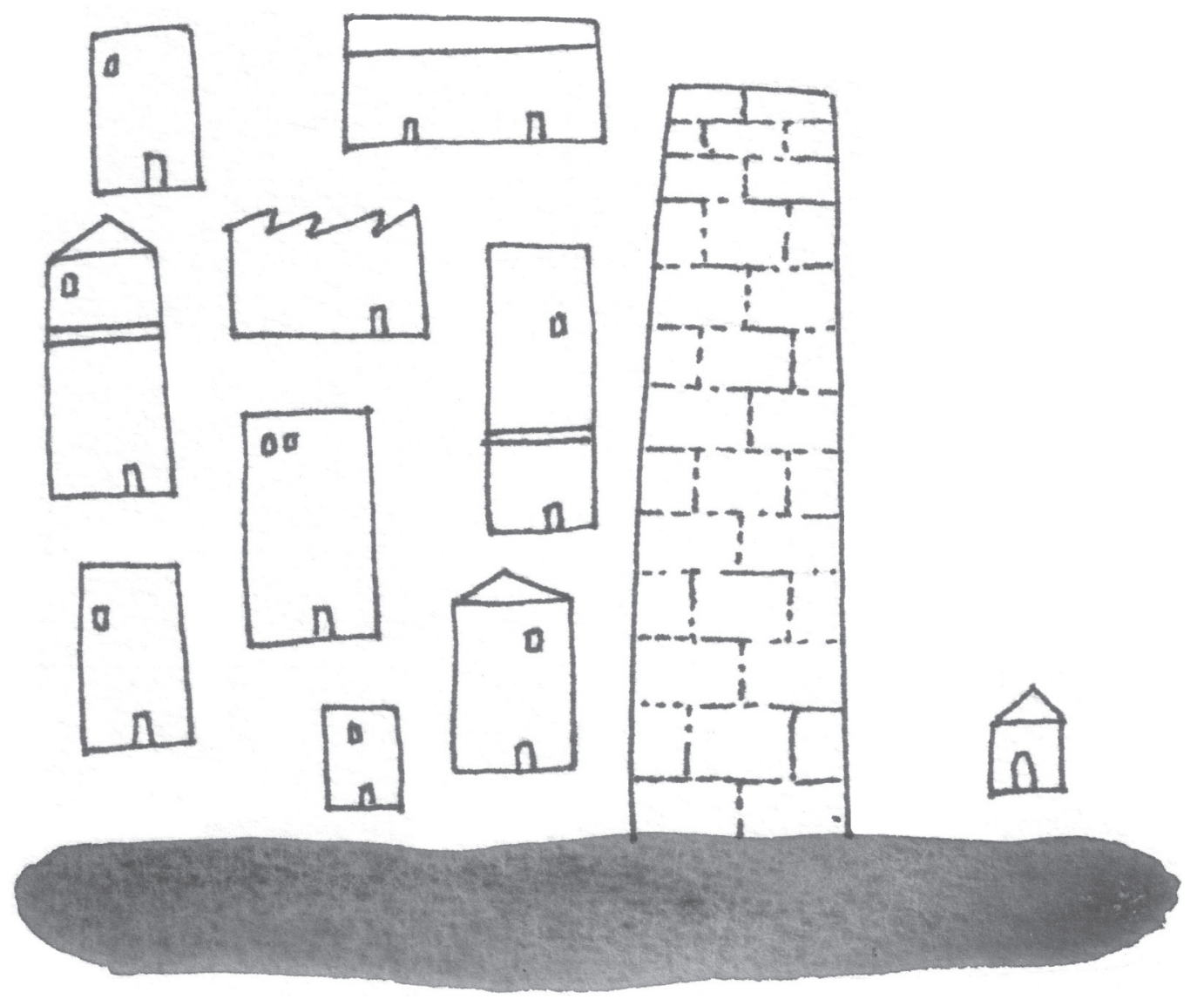

6 Entrevista con el doctor Marcos Arana, Nuevo Huixtán, septiembre de 2012.

7 Entrevista con el doctor Marcos Arana, Nuevo Huixtán, septiembre de 2012. 
horneado en Quetzaltenango; blusas y cortes (faldas indígenas) confeccionadas en los municipios de Nentón o San Miguel Acatán; medicinas naturales, dulces tradicionales, productos de ferretería o de abarrotes traídos desde el departamento de Huehuetenango, Guatemala, etcétera. Esos senderos también son usados por aquellos que desde Chiapas visitan a sus familiares, pues reducen horas de traslado y no se ven en la necesidad de pagar ninguna cuota de paso vehicular, como exigen las autoridades guatemaltecas en el punto migratorio conocido como La Mesilla, que es la continuación de la carretera Panamericana que atraviesa México y Latinoamérica.

No obstante, esos caminos comienzan a ser también transitados por talamontes y narcotraficantes, lo cual pone en riego a la población que hasta hoy los usa como paso habitual. Yo misma he recorrido esas sendas en diversas ocasiones. Me gusta hacerlo con gente de las comunidades porque me narran históricamente el paisaje. Donde yo veo montañas ellos ven recuerdos, rutas del refugio, sitios de contacto entre la guerrilla y la población civil, excampamentos, entierros colectivos, experiencias que los marcaron para siempre y que están enclavadas en el paisaje. Yo tan sólo veo verde, maleza, árboles, pero ellos ven medicina. Y donde únicamente veo cerros y ríos, ellos ven el camino a sus aldeas originarias. El paisaje es similar en ambos lados de la frontera, es tan imponente como la violencia que ahí se ha vivido.

La enorme necesidad de producir los alimentos básicos y criar sus animales en terrenos propios generó que los refugiados fueran pioneros de la migración en Chiapas, y que después se convirtieran en guías de muchos campesinos mexicanos. Comenzaron a migrar cuando finalizó la ayuda internacional y se les dio la posibilidad de naturalizarse como mexicanos. Algunos lo habían sido antes de la guerra.

En la actualidad, migran también las mujeres y las y los jóvenes. Se trata, por tanto, de una población que no ha dejado de desplazarse desde hace décadas; estos individuos son empujados siempre por modelos económicos que los convierten en campesinos sin tierra, en obreros sin trabajo, en indocumentados. Como explica Basch (1992 cit. en Camus, 2007: 31): "construyen campos de interacción social que vinculan a su país de origen y su país de establecimiento, y que atraviesan fronteras geográficas, culturales y políticas, de manera que la salida de la gente no supone su desvinculación con el territorio de origen".
Son varios los trabajos antropológicos que describen el circuito comercial existente desde Guatemala, pasando por México y llegando a distintas ciudades de Estados Unidos, en donde se trasladan no sólo músicos, danzantes, sacerdotes mayas o líderes religiosos, sino todos aquellos objetos requeridos para la realización de fiestas patronales en las que la población migrante $\mathrm{y}$ / o refugiada refrenda su pertenencia cultural (véanse, por ejemplo, Odem, 2007; Martínez Manzanero, 2016; Ruiz Lagier, 2017). Así es como el territorio fronterizo es reapropiado y vivido en su cotidianidad. Considero que la población que se ha refugiado en México y después ha migrado a Estados Unidos y Canadá, también ha redimensionado simbólicamente el territorio maya. ${ }^{8}$ Estas poblaciones transnacionales adquieren nuevos contenidos culturales, comportamientos y roles sociales. Amplían los límites de un espacio vivido mediante el imaginario del "norte", que hoy en día pareciera ser un rito de paso entre los jóvenes.

Es mayor la comunicación con Guatemala y "el norte", donde hay acceso a internet gratuito (telesecundarias y/o bachilleratos técnicos). La población fortalece la comunicación con familiares que no ven desde el refugio o que migraron, a través de herramientas electrónicas como WhatsApp, Facebook y Skype. Internet ha dinamizado también la escritura de la lengua materna en algunas comunidades. Los jóvenes han incursionado en ello de manera independiente a las normas establecidas por los lingüistas. Mezclan el español y su lengua, apropiándosela y dándole vitalidad.

Existen celebraciones que convocan a los pueblos divididos entre el norte y el sur. El Día de Todos los Santos se reproduce, de algún modo, la ruta del refugio. De Guatemala y Estados Unidos concurren a los lugares donde enterraron a sus muertos. Visitan los panteones creados para los excampamentos de refugio, pero también los caminos de la montaña donde cruzaron la frontera y fueron muriendo los más enfermos.

A mi parecer, la antropología tiene una deuda con la población refugiada protestante, que no realiza este tipo de celebraciones religiosas tan atractivas para el observador externo. Sería revelador saber cuáles son los referentes culturales de la población protestante en el nuevo territorio. Qué mecanismos simbólicos le dan contenido a su identidad colectiva para vivir como pueblo q'anjobal, chuj, mam o akateko mexicano o migrante en Estados Unidos.

8 Este fenómeno ha sido definido como comunidades transnacionales o extraterritoriales por autores como Oehmichen Bazán (2001) y Martínez Casas (2001). 


\section{Conclusiones}

La población akateka, mam, chuj, poptí, q’anjobal, forma ahora parte de los pueblos indígenas del país, según la Comisión Nacional para el Desarrollo de los Pueblos Indígenas, empero, las acciones dirigidas a robustecer la cultura local son pocas o inexistentes. No hay materiales ni proyectos culturales que fortalezcan a estas comunidades y las empodere frente a las relaciones de discriminación, que no son sólo locales, sino que obedecen a un modelo nacional que promueve, a través de sus medios de comunicación, patrones de belleza y prácticas culturales ajenos a la población indígena.

La falta de reconocimiento cultural es reflejo de la discriminación y el racismo del país, que considera los conocimientos ancestrales como costumbres o saberes locales sin fundamento científico.

Ante este escenario, vale preguntar si la población naturalizada no perdió más de lo que ganó al adquirir la ciudadanía mexicana. A pesar de que hace 30 años se encontraban en condiciones de vulnerabilidad extrema, los niños recibían contenidos en su idioma y desde su realidad rural; les enseñaban su historia como pueblos indígenas mayas, y gozaban de promotores de educación que trabajaban comprometidos con su comunidad. Esto ya no lo tienen los niños de la segunda o tercera generación nacida en México.

Quienes estudiamos la apropiación del espacio debemos analizar distintos elementos relacionados con cómo se vive el territorio en el día a día. Para entender por qué hay tantas diferencias entre unas y otras comunidades de origen guatemalteco es indispensable saber cuáles fueron sus experiencias sociopolíticas en la guerra, en el refugio, si anhelaron o no retornar, si se fraccionaron debido a esas decisiones, si los líderes regresaron y quienes se asentaron en Chiapas quedaron desorganizados, si perdieron credibilidad los líderes históricos, si las nuevas generaciones desean retomar esa experiencia o sus horizontes son otros. Es decir, la vivencia diaria que se objetiviza en el espacio a través de la acción cotidiana.

Sólo atendiendo la dimensión sociopolítica y cultural tendremos un panorama general que explique por qué se construyen, o no, alianzas políticas, trabajo colectivo o lazos de solidaridad entre la población, a pesar de la diversidad etnolingüística o religiosa; o por qué aquellos con un origen común y una misma historia de refugio no siempre logran hacer comunidad. Cruzar esta información con la de las políticas públicas, esto es, la mirada institucional, resulta indispensable. La dimensión oficial nos explica sobre la frontera-límite, la mirada etnográfica que se relaciona con la geografía humana nos habla de la frontera-frente, nos da cuenta de por qué el refugio no siempre derivó en comunidades con fuerte cohesión política y cultural.

Lo que hoy veo en la zona fronteriza conocida como zona selva es una población empobrecida y discriminada socioculturalmente, un gobierno federal que no ha dado seguimiento al proceso de integración, y muestra de ello es que la Comar no cuenta con un informe final del proceso de naturalización, sus estadísticas son contradictorias y confusas, y sus archivos no sólo están desordenados, sino incluso perdidos, en bodegas de la Ciudad de México pertenecientes a la Secretaría de Relaciones Exteriores. Quienes no concluyeron su proceso migratorio son apátridas, producto del refugio prolongado, sin certeza jurídica sobre su propia nacionalidad.

Por lo anterior, finalizo insistiendo en que no debemos hablar de "el refugio guatemalteco" como algo homogéneo. Son varios procesos distintos, inacabados algunos, que deben analizarse regionalmente. De igual modo, si nos referimos a la frontera sur como frontera-límite, no describimos ninguna cosa. La frontera es una idea abstracta que poco o nada dice de quienes la habitan.

\section{Fuentes}

Arellano Sánchez, José

Y MARGARITA SANTOYO

1996 "Racismo y nuevos sujetos sociales en Chiapas. El surgimiento del EZLN", en VI Jornadas Lascasianas: La problemática del racismo en los umbrales del siglo XXI, Instituto de Investigaciones Jurídicas-Universidad Nacional Autónoma de México (Cuadernos del Instituto), México, pp. 139-169.

Arriaga Rodríguez, JuAn CARlos

2011 "El concepto frontera en la geografía humana",

Camus, Manuela en Perspectiva Geográfica, vol. 16, pp. 71-97.

2007 "Introducción”, en Manuela Camus (ed.), Comunidades en movimiento. La migración internacional en el norte de Huehuetenango, Instituto Centroamericano de Desarrollo y Estudios Sociales/Centro de Estudios y Documentación de la Frontera Occidental de Guatemala,

DE Vos, JAN Guatemala, pp. 15-54

1993 Las fronteras de la frontera sur, Universidad Juárez Autónoma de Tabasco/Centro de Investigaciones y Estudios Superiores en Antropología Social, México.

DE Vos, JAN

2002 "La frontera sur y sus fronteras: una visión histórica", en Edith Kauffer, Identidades, migraciones y género en la frontera sur de México, $\mathrm{El}$ Colegio de la Frontera Sur, México, pp. 49-68.

Franco, LEONARDO

1999 "Un episodio controvertido en la historia del refugio", en Alto Comisionado de las Naciones 
Unidas para los Refugiados, La integración de los refugiados guatemaltecos en Chiapas. Resumen ejecutivofinal, Secretaría de Gobernación / Alto Comisionado de las Naciones Unidas para los Refugiados, México, pp. 77-81.

Freyermuth, Graciela

Y NANCY GODFREY

1993 Refugiados guatemaltecos en México, Centro de Investigaciones y Estudios Superiores en Antropología Social/Instituto Chiapaneco de Cultura, México.

GutiÉRREZ, JAVIER

2001 La migración indígena en la frontera sur, Instituto Nacional Indigenista, México.

Hernández, AídA

2012 Sur profundo. Identidades en la frontera Chiapas-Guatemala, Centro de Investigaciones y Estudios Superiores en Antropología Social, México.

Martínez Casas, Regina

2001 "Una cara indígena de Guadalajara: resignificación de la cultura otomí en la ciudad", tesis de doctorado, Universidad Autónoma Metropolitana-Iztapalapa, México.

Martínez Manzanero, Adriana

2016 "Las artes del camino de la memoria. Movilidad y otros pasajes del refugio guatemalteco", tesis de doctorado, El Colegio de Michoacán, Zamora.

MonteJo, Victor

1999 Voices from Exile. Violence and Survival in Modern Maya History, University of Oklahoma Press, Norman.

Muñoz, PráXedes

y Verónica Ruiz LAgier

2014 "La educación no oficial en niños refugiados, desplazados, y en resistencia por el conflicto interno en Guatemala”, en Adela Franzé y David Poveda (eds.), Contextos múltiples de socialización y aprendizaje. Un análisis desde la etnografía de la educación, Traficante de Sueños (Miradas y Voces Etnográficas en la Educación), Madrid.
Navarrete, Carlos

1980 "Las rutas de comunicación prehispánica en los Altos Cuchumatanes, un proyecto arqueológico y etnohistórico", en Antropología e Historia de Guatemala, II época, núm. 2, pp. 7-19.

Odem, Mary E.

2007 "Inmigración trasnacional y organización maya en el sur de Estados Unidos", en Manuela Camus (ed.), Comunidades en movimiento. La migración internacional en el norte de Huehuetenango, Instituto Centroamericano de Desarrollo y Estudios Sociales / Centro de Estudios y Documentación de la Frontera Occidental de Guatemala, Guatemala, pp. 205-223.

Oehmichen Bazán, Cristina

2001 "Mujeres indígenas migrantes en el proceso de cambio cultural. Análisis de las normas de control social y relaciones de género en la comunidad extraterritorial", tesis de doctorado, Facultad de Filosofía y Letras-Universidad Nacional Autónoma de México, México.

Pohlenz, JuAn

1985 "La conformación de la frontera entre México y Guatemala. El caso de Nuevo Huixtán en la selva chiapaneca", en Andrés Fábregas et al., Laformación histórica de la frontera sur, Centro de Investigaciones y Estudios Superiores en Antropología Social, México, pp. 23-130.

Ruiz LAgier, Verónica

2012a Ser mexicano en Chiapas, Instituto Nacional de Antropología e Historia, México.

RUIZ LAGIER, VeróNICA

2012b "El eterno retorno de los refugiados guatemaltecos", en La Jornada, suplemento Ojarasca, núm. 187 <http: / www.jornada.com.mx/2012/11/ 10/oja-retorno.html>.

Ruiz LAgier, Verónica

2017 "Los usos estratégicos de la tradición. El baile del venado y la conquista entre los acatekos de La Gloria, Chiapas", en Gunther Dietz, Christiane Stallaert e Irlanda Villegas (coords.), El poder de la memoria. Reconstrucción de identidades colectivas en el triángulo atlántico, Universidad Veracruzana, México, pp. 243-258. 